\title{
ОЦЕНКА ВЛИЯНИЯ ПОЛИМОРФИЗМОВ ГЕНОВ АВСВ1 И СУРЗА5НА СТЕПЕНЬ ИЗМЕНЕНИЯ ПРОТРОМБИНОВОГО ВРЕМЕНИ ПОД ВЛИЯНИЕМ РИВАРОКСАБАНА У ПАЦИЕНТОВ ПОСЛЕ ЭНДОПРОТЕЗИРОВАНИЯ КРУПНЫХ СУСТАВОВ НИЖНИХ КОНЕЧНОСТЕЙ
}

\author{
Д. А. Сычев ${ }^{1}$, Р. М. Миннигулов ${ }^{2}$, К. А. Рыжикова ${ }^{1}$, И. Ю. Юдина ${ }^{2}$ А. В. Лычагин², Т. Е. Морозова² \\ ${ }^{1}$ Российская медицинская академия непрерывного профессионального образования, Москва \\ 2 Первый Московский государственный медицинский университет имени И. М. Сеченова (Сеченовский университет), Москва
}

\begin{abstract}
Несмотря на высокую эффективность и безопасность применения ривароксабана по сравнению с варфарином, в клинической практике наблюдаются редкие случаи крупных геморрагических осложнений, которые могут значительно ухудшать качество жизни пациентов или быть летальными. Остается открытым вопрос, насколько фармакогенетические тесты позволят профилактировать развитие таких неблагоприятных событий. Целью работы было оценить влияние носительства полиморфизмов АВСВ1 3435C>T (rs1045642) и CYP3A5 6986A>G (rs776746) на изменение протромбинового времени (ПВ) у пациентов, принимающих для тромбопрофилактики ривароксабан после эндопротезирования крупных суставов нижних конечностей. В исследование были включены 65 пациентов. Генотипирование проводили с помощью ПЦР в реальном времени. Для определения ПВ венозную кровь отбирали на 5 сутки приема антикоагулянта 2 раза: за 1 ч до приема ривароксабана и через 3 ч после приема. Вычислив \%

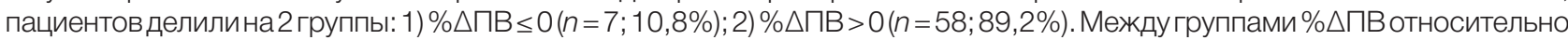
распределения генотипов полиморфизма rs1045642 была определена статистически достоверная разница $\left(\chi^{2}=6,64\right.$; $p=0,027)$. Относительно распределения генотипов полиморфизма rs776746 статистически значимой разницы между группами \% $\Delta$ ПВ обнаружено не было $\left(\chi^{2}=0,101 ; p=1,0\right)$. Выявлено статистически значимое влияние полиморфизма rs1045642 на характер изменения ПВ у пациентов, принимающих с целью тромбопросилактики ривароксабан после эндопротезирования крупных суставов нижних конечностей.
\end{abstract}

Ключевые слова: ривароксабан, фармакогенетика, протромбиновое время, эндопротезирование тазобедренного сустава, эндопротезирование коленного сустава, тромбопрофилактика

Финансирование: работа выполнена при финансовой поддержке Российского научного фонда, проект 16-15-00227 «Проведение фундаментальных научных исследований и поисковых научных исследований по приоритетным тематическим направлениям исследований».

Благодарности: Богданову М. М., врачу клиники травматологии, ортопедии и патологии суставов УКБ №1 Первого МГМУ им. И. М. Сеченова за помощь в наборе пациентов.

$\bigotimes$ Для корреспонденции: Радик Мисхатович Миннигулов

ул. Большая Пироговская, д. 2, стр. 4, г. Москва, 119435; radik.minnigulov@gmail.com

Статья получена: 08.10.2018 Статья принята к печати: 30.10.2018

DOI: $10.24075 /$ vrgmu.2018.068

\section{EVALUATION OF THE RIVAROXABAN-INFLUENCED EFFECT OF ABCB1 AND CYP3A5 GENE POLYMORPHISMS ON PROTHROMBIN TIME IN PATIENTS AFTER TOTAL HIP OR KNEE REPLACEMENT SURGERY}

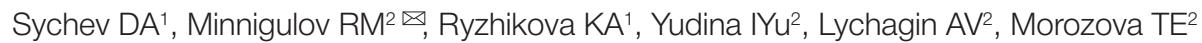

Russian Medical Academy of Continuous Professional Education, Moscow

2 Sechenov First Moscow State Medical University (Sechenov University), Moscow

Rivaroxaban is a safer and more effective alternative to warfarin. However, there are reports of some cases of major hemorrhagic complications associated with rivaroxaban that significantly impair the patients' quality of life and can lead to a fatality. Personalized therapy, including pharmacogenetic testing, may help prevent such adverse events. This study aimed to investigate how $A B C B 1$ 3435C>T (rs1045642) and CYP3A5 6986A>G (rs776746) gene polymorphisms, when carried by a patient taking rivaroxaban to prevent thrombosis after total hip or knee replacement surgery, affect prothrombin time (PT). Sixty-five patients participated in the study. Their genotypes were identified by PCR in real time. To learn PT peculiar to each patient, we collected venous blood on the $5^{\text {th }}$ day of their anticoagulation therapy, 1 hour before they took rivaroxaban and 3 hours after. Having calculated \% $\triangle \mathrm{PT}$, we divided the patients into 2 groups: 1) \% $\Delta \mathrm{PT} \leq 0$ ( $n=7 ; 10.8 \%) ; 2) \% \Delta \mathrm{PT}>0(n=58 ; 89.2 \%)$. Regarding the distribution of rs 1045642 polymorphism, we determined the difference between the groups to be statistically significant $\left(\alpha^{2}=6.64 ; p=0.027\right)$. As for rs776746 polymorphism, the difference was insignificant $\left(\chi^{2}=0.101 ; p=1.0\right)$. We discovered that rs1045642 polymorphism has a significant effect on PT variance in patients taking rivaroxaban to prevent thrombosis after total hip or knee replacement surgery.

Keywords: rivaroxaban, pharmacogenetics, prothrombin time, hip replacement surgery, knee replacement surgery, thromboprophylaxis

Funding: this study was supported by Russian Science Foundation, project 16-15-00227 "Conducting fundamental scientific research and exploratory research on priority thematic research areas".

Acknowledgments: the authors would like to thank M. M. Bogdanov, practitioner with the Clinic of Traumatology, Orthopedics and Joint Pathology of the 1st Hospital of I. M. Sechenov First Moscow State Medical University, for his assistance in enlisting patients.

$\triangle$ Correspondence should be addressed: Radik M. Minnigulov

Bolshaya Pirogovskaya 2, bldg. 4, Moscow, 119435; radik.minnigulov@gmail.com

Received: 08.10.2018 Accepted: 30.10.2018

DOI: $10.24075 /$ brsmu.2018.068 
Тромбоз глубоких вен (ТГВ) нижних конечностей и тромбоэмболия легочной артерии (ТЭЛА) остаются одной из важнейших проблем в клинической практике. К группе высокого риска развития ТЭЛА относятся пациенты, перенесшие эндопротезирование крупных суставов нижних конечностей. Распространенность ТГВ у пациентов после тотального эндопротезирования тазобедренного сустава (ТЭТС) или коленного сустава (ТЭКС) без антикоагулянтной тромбопрофилактики составляет около 50-60\% [1] Фатальные случаи ТЭЛА могут развиться примерно у 1 из 500 пациентов после ТЭТС [2]. Количество проводимых в Российской Федерации ТЭТС растет с каждым годом, и в настоящее время ежегодно выполняется около 25 операций ТЭТС на 100000 человек [3].

В последнее время для тромбопрофилактики после эндопротезирования крупных суставов нижних конечностей в распоряжении врачей появились прямые пероральные антикоагулянты, которые удобны в использовании, не требуют лабораторного контроля и обладают хорошим профилем эффективности и безопасности. В этой статье речь пойдет о ривароксабане, который является прямым ингибитором фактора Ха. В 2011 г. ОН был одобрен FDA для тромбопрофилактики у пациентов после эндопротезирования крупных суставов нижних конечностей [4].

Около 18\% от дозы ривароксабана метаболизируется с помощью CYP3A4/5, 14\% - через CYP2J2. На 36\% ривароксабан в неизменном виде выводится через почки, включая активную секрецию с помощью Р-гликопротеина (P-gp) и BCRP (Breast Cancer Resistance Protein) [5].

P-gp представляет собой крупный мембранный белок, транспортирующий лекарственные средства из клетки наружу. Располагается на поверхности эпителиальных клеток, выстилающих тонкий и толстый кишечник, панкреатический проток, в мембране желчных канальцев печени, в проксимальных канальцах почек и в надпочечниках, также обнаруживается в эндотелиоцитах гистогематических барьеров (гематоэнцефалического, гематоовариального, гематотестикулярного и гематоплацентарного) [6]. Р-gр кодируется геном ABCB1, располагающимся на 7-й хромосоме (7q21.12) [7]. Наиболее распространенными однонуклеотидными полиморфизмами (SNP) гена ABCB1 являются 1236T>C (rs1128503), 2677T>G/A (rs2032582) и 3435T>C (rs1045642) [8]. В нашей работе мы исследовали влияние полиморфизма ABCB1 3435C>T (rs1045642).

Белки СҮРЗА4 и СҮРЗА5 вместе составляют около 30\% от печеночного цитохрома Р450, и примерно половина лекарственных средств, которые метаболизируются посредством цитохрома Р450, служат субстратами СҮРЗА. СУРЗА4 и СУРЗА5 экспрессируются в печени и кишечнике, причем экспрессия СУРЗАБ преобладает во внепеченочных тканях. Ген СУРЗА5 расположен на 7-й хромосоме (7q22.1) и кодирует белок из 502 аминокислот. Наиболее распространенным SNP гена СYРЗА5 является 6986A $>G$ (rs776746). Стоит отметить, что носители генотипа СУРЗА5 6986GG полностью не экспрессируют изофермент СYРЗА5 [9].

По данным программы исследований RECORD 1-4 [10-13], несмотря на хороший профиль эффективности и безопасности ривароксабана, назначаемого с целью тромбопрофилактики после эндопротезирования крупных суставов нижних конечностей, у 2,87\% пациентов наблюдали случаи небольших клинически значимых кровотечений, в том числе гематомы в области оперативного вмешательства, которые могут инсицироваться. Данное осложнение требует удаления эндопротеза, что ухудшает качество жизни пациента и оказывает дополнительную финансовую нагрузку на систему здравоохранения. Для предотвращения подобных нежелательных побочных реакций в настоящее время начинают применять технологии персонализированной медицины, в частности, фармакогенетическое тестирование.

Целью данного исследования было оценить влияние носительства полиморфизмов ABCB1 3435C > T (rs1045642) и CYP3A5 6986A>G (rs776746) на изменение протромбинового времени (ПВ) у пациентов, принимающих с целью тромбопрофилактики ривароксабан после эндопротезирования крупных суставов нижних конечностей.

\section{МАТЕРИАЛЫ И МЕТОДЫ}

Протокол исследования был рассмотрен и одобрен местным этическим комитетом при ФГАОУ ВО Первый МГМУ им. И. М. Сеченова Минздрава России (Сеченовский Университет) (протокола заседания № 0317 от 19.04.2017). Критерии включения в исследование: пациенты обоих полов; возраст $\geq 18$ лет; состояние после первичного ТЭТС или ТЭКС; тромбопрофилактика с использованием ривароксабана в дозе 10 мг 1 раз В сутки; наличие информированного добровольного согласия. Критерии исключения: наличие фибрилляции предсердий с сопутствующей антикоагулянтной тромбопрофилактикой; геморрагический диатез; наличие в анамнезе острого внутричерепного заболевания или геморрагического инсульта в течение последних трех месяцев; желудочно-кишечное кровотечение, гематурия, язвенная болезнь желудка или двенадцатиперстной кишки в течение последних 6 месяцев; тяжелые заболевания печени; повышение печеночных трансаминаз (АЛТ и АСТ) $\geq 2$ верхних границ нормы в прошлом месяце; тяжелая почечная недостаточность (КK < 30 мл/мин); развернутая стадия онкологического заболевания; беременность, период лактации; возраст < 18 лет.

В исследование были включены 65 пациентов после ТЭТС ( $n=19 ; 29,2 \%)$ или ТЭКС $(n=46 ; 70,8 \%)$. Среди них были 48 (73,8\%) женщин и 17 (26,2\%) мужчин в возрасте от 24 до 83 лет (средний возраст $59 \pm 12$ лет). В соответствии с инструкцией по применению лекарственного средства в послеоперационном периоде с целью тромбопрофилактики все пациенты получали ривароксабан 10 мг 1 раз в сутки. Пациенты, перенесшие ТЭТС, получали ривароксабан в течение 35 дней, а пациенты, перенесшие ТЭКС, - в течение 14 дней [14].

Материалом для выделения ДНК служила венозная кровь. Кровь для генотипирования собирали в вакуумные пробирки Vacuette ${ }^{\circledast}$ с антикоагулянтом ЭДТА-КЗ, объемом 4 мл. Генотипирование по полиморфизмам ABCB1 3435С> Т (rs1045642) и СҮРЗА5 6986A>G (rs776746) проводили с использованием полимеразной цепной реакции (ПЦР) в реальном времени на ДНК-амплификаторе CFX96 Touch ${ }^{\text {тм }}$ Real-Time PCR Detection System (Bio-Rad Laboratories, Inc.; USA) на базе Научно-исследовательского центра ФГБОУ ДПО РМАНПО Минздрава России.

Фармакодинамику ривароксабана оценивали посредством определения ПВ. Забор венозной крови для определения ПВ осуществляли 2 раза на 5-е сутки приема антикоагулянта: за 1 ч до приема $\left(\Pi_{1}\right)$ и через 3 ч после приема ривароксабана $\left(П \mathrm{~B}_{2}\right)$. Кровь для определения ПВ собирали в вакуумные пробирки BD Vacutainer ${ }^{\oplus}$ с цитратом 
натрия 3,2\%, объемом 2,7 мл. ПВ определяли мануально с использованием Техпластин-теста (Технология-Стандарт; Россия) в соответствии с инструкцией производителя.

Для определения изменений в значениях ПВ проводили расчет процентного изменения ПВ по следующей формуле: $\% \Delta \Pi \mathrm{B}=\left(\sqcap \mathrm{B}_{2}-\sqcap \mathrm{B}_{1}\right) / \sqcap \mathrm{B}_{1} \times 100 \%$. В зависимости от значений процентного изменения ПВ пациентов делили на 2 группы: 1) пациенты, у которых \% $\Delta \Pi \mathrm{B} \leq 0$; 2) пациенты с $\% \Delta П \mathrm{~B}>0$.

Частоту встречаемости генотипов исследуемых полиморфизмов генов проверяли на соответствие распределению согласно закону Харди-Вайнберга с применением онлайн-калькулятора [15]. Для определения разницы между группами процентного изменения ПВ в зависимости от полиморфизмов ABCB1 3435C>T (rs1045642) и СУР3А5 6986A>G (rs776746) рассчитывали статистический критерий хи-квадрат Пирсона. Обработку результатов проводили с применением статистической программы PASW Statistics 18 (2009 г.).

\section{РЕЗУЛЬТАТЫ ИССЛЕДОВАНИЯ}

Пациенты были распределены в зависимости от генотипа полиморфизма ABCB1 3435C>T (rs1045642) следующим образом: пациенты с генотипом 3435СC $n=17$ (26,2\%), с генотипом 3435СТ $n=27$ (41,5\%), с генотипом 3435TТ $n=21$ (32,3\%). В отношении носительства генотипов полиморфизма СҮРЗА5 6986A>G (rs776746) были выявлены пациенты с генотипом 6986AG $n=7$ (10,8\%) и с генотипом 6986GG $n=58$ (89,2\%) (табл. 1).
Распределения генотипов полиморфизмов АBCB1 3435C>T (rs1045642) и CYP3A5 6986A>G (rs776746) не отклонялись от равновесия Харди-Вайнберга $\left(\chi^{2}=1,79\right.$; $p=0,409$ и $\chi^{2}=0,21 ; p=0,9$ соответственно).

В группе пациентов, включенных в исследование, среднее значение ПВ (измеренное за 1 ч до приема ривароксабана) составило 15,5 \pm 4,1 с, а среднее значение $\Pi_{2}$ (измеренное через 3 ч после приема ривароксабана) - 19,1 \pm 3,2 с. Другие средние значения ПВ в зависимости от генотипов полиморфизмов ABCB1 3435C > Т (rs1045642) и СУРЗА5 6986A>G (rs776746) представлены в табл. 2.

Индивидуальный анализ изменчивости ПВ показал, что у 7 (10,8\%) из 65 пациентов имела место парадоксальная реакция: ПВ на фоне приема ривароксабана уменьшалось либо оставалось без изменений (\% $\triangle П \mathrm{~B} \leq 0)$. У остальных 58 (89,2\%) пациентов, как и предполагалось, ПВ на фоне приема ривароксабана увеличилось (\% $\Delta П \mathrm{~B}>0)$. В группе с $\% \triangle П \mathrm{~B} \leq 0$ у 6 пациентов $(85,7 \%)$ наблюдали носительство генотипа ABCB1 3435CT, в то время как носителей генотипа $A B C B 1$ 3435TТ в данной группе обнаружено не было. С помощью статистического критерия хи-квадрат Пирсона была обнаружена статистически достоверная разница между группами процентного изменения ПВ в зависимости от распределения генотипов полиморфизма $A B C B 1$ 3435C>T (rs1045642) $\left(\chi^{2}=6,64 ; p=0,027\right)$ (табл. 3).

Наиболее существенный вклад в различие между группами процентного изменения ПВ вносили пациенть с генотипом ABCB1 3435CT. В табл. 4 представлено «ручное» определение достоверности различий набора

Таблица 1. Распределение генотипов полиморфизма АВCB1 3435C>T (rs1045642) и полиморфизма CYP3A5 6986A>G (rs776746) среди пациентов, получавших ривароксабан после эндопротезирования крупных суставов нижних конечностей

\begin{tabular}{|c|c|c|c|}
\hline \multirow{2}{*}{ Полиморфизмы } & \multirow{2}{*}{ Генотип } & \multicolumn{2}{|c|}{ Количество пациентов } \\
\hline & & абсолютное & относительное, \% \\
\hline \multirow{3}{*}{$A B C B 13435 \mathrm{C}>\mathrm{T}(\mathrm{rs} 1045642)$} & $A B C B 13435 C C$ & 17 & 26,2 \\
\hline & $A B C B 13435 C T$ & 27 & 41,5 \\
\hline & ABCB1 3435TT & 21 & 32,3 \\
\hline \multirow{2}{*}{ CYPЗА5 6986A>G (rs776746) } & CYP3A5 6986AG & 7 & 10,8 \\
\hline & CYP3А5 6986GG & 58 & 89,2 \\
\hline
\end{tabular}

Таблица 2. Среднее значение протромбинового времени по группе и в зависимости от генотипов полиморфизмов ABCB1 3435C>T (rs1045642) и CYР3А5 6986A>G (rs776746) у пациентов, получавших ривароксабан после эндопротезирования крупных суставов нижних конечностей

\begin{tabular}{|c|c|c|c|c|c|}
\hline \multirow[b]{2}{*}{ Пациенты, включенные в исследование $(n=65)$} & Среднее ПВ & Среднее ПВ & $p$ & Среднее $\triangle \Pi \mathrm{B}, \mathrm{c}$ & Среднее \% $\triangle П В, \%$ \\
\hline & $15,5 \pm 4,1$ & $19,1 \pm 3,2$ & $\begin{array}{c}t=9.185 \\
p=2,7 \times 10^{-13}\end{array}$ & $3,6 \pm 4,9$ & $27,4 \pm 26,3$ \\
\hline$A B C B 13435 C C$ & $14,8 \pm 2,1$ & $19,8 \pm 3,7$ & $\begin{array}{c}t=5.48 \\
p=5,03 \times 10^{-5}\end{array}$ & $4,95 \pm 3,3$ & $34,7 \pm 24,5$ \\
\hline$A B C B 13435 C T$ & $16,0 \pm 5,7$ & $18,4 \pm 3,0$ & $\begin{array}{c}t=4.074 \\
p=3,85 \times 10^{-4}\end{array}$ & $2,4 \pm 6,8$ & $22,8 \pm 32,9$ \\
\hline$A B C B 13435 T T$ & $15,5 \pm 2,8$ & $19,5 \pm 2,7$ & $\begin{array}{c}t=6,652 \\
p=1,77 \times 10^{-6}\end{array}$ & $4,02 \pm 2,2$ & $27,3 \pm 15,8$ \\
\hline CYP3A5 6986AG & $14,3 \pm 1,9$ & $20,6 \pm 3,1$ & $\begin{array}{l}t=5,358 \\
p=0,002\end{array}$ & $6,3 \pm 4,2$ & $47,3 \pm 34,8$ \\
\hline CYP3A5 6986GG & $15,7 \pm 4,3$ & $18,9 \pm 3,1$ & $\begin{array}{c}t=7,798 \\
p=1,49 \times 10^{-10}\end{array}$ & $3,2 \pm 4,95$ & $25,0 \pm 24,3$ \\
\hline
\end{tabular}

Таблица 3. Распределение генотипов полиморфизма АВСB1 3435C>T (rs1045642) в зависимости от процентного изменением ПВ у пациентов, получавших ривароксабан $(n=65)^{*}$ после эндопротезирования крупных суставов нижних конечностей

\begin{tabular}{|l|c|c|}
\hline & $\% \Delta \Pi \mathrm{B} \leq 0$ & $\% \Delta \Pi \mathrm{B}>0$ \\
\hline$A B C B 13435 \mathrm{CC}$ & $1(14,3 \%)$ & $16(27,6 \%)$ \\
\hline$A B C B 13435 \mathrm{CT}$ & $6(85,7 \%)$ & $21(36,2 \%)$ \\
\hline$A B C B 13435 \mathrm{TT}$ & $0(0 \%)$ & $21(36,2 \%)$ \\
\hline
\end{tabular}

Примечание: * $\chi^{2}=6,64 ; p=0,027$. 
Таблица 4. Определение существенности различий фактического и ожидаемого распределений генотипов полиморфизма АBCB1 3435С>Т (rs1045642) в группах процентного изменения ПВ

\begin{tabular}{|c|c|c|c|}
\hline \multicolumn{4}{|c|}{ Фактическое распределение генотипов в группах процентного изменения ПВ } \\
\hline & $\% \Delta \Pi \mathrm{B} \leq 0$ & $\% \Delta \Pi \mathrm{B}>0$ & Bcero \\
\hline$A B C B 13435 C C$ & 1 & 16 & 17 \\
\hline$A B C B 13435 C T$ & 6 & 21 & 27 \\
\hline$A B C B 13435 T T$ & 0 & 21 & 21 \\
\hline Всего & 7 & 58 & 65 \\
\hline \multicolumn{4}{|c|}{ Ожидаемое распределение генотипов в группах процентного изменения ПВ } \\
\hline & $\% \Delta \Pi \mathrm{B} \leq 0$ & $\% \Delta \Pi \mathrm{B}>0$ & Bсего \\
\hline$A B C B 13435 C C$ & 2 & 15 & 17 \\
\hline ABCB13435CT & 3 & 24 & 27 \\
\hline$A B C B 13435 T T$ & 2 & 19 & 21 \\
\hline Всего & 7 & 58 & 65 \\
\hline \multicolumn{4}{|c|}{ Существенность различий фактического и ожидаемого распределений генотипов } \\
\hline & $\% \Delta \Pi \mathrm{B} \leq 0$ & $\% \Delta \Pi \mathrm{B}>0$ & Bсего \\
\hline$A B C B 13435 C C$ & 0,50 & 0,07 & 0,57 \\
\hline ABCB13435CT & 3,00 & 0,38 & 3,38 \\
\hline$A B C B 13435 T T$ & 2,00 & 0,21 & 2,21 \\
\hline Всего & 5,50 & 0,66 & 6,16 \\
\hline
\end{tabular}

Таблица 5. Распределение генотипов полиморфизма СУР3А5 6986A>G (rs776746) в зависимости от процентного изменения ПВ у пациентов, получавших ривароксабан $(n=65)^{\star}$ после эндопротезирования крупных суставов нижних конечностей

\begin{tabular}{|l|c|c|}
\hline & $\% \Delta \Pi \mathrm{B} \leq 0$ & $\% \Delta \Pi \mathrm{B}>0$ \\
\hline CYP3A5 6986AG & $1(14,3 \%)$ & $6(10,3 \%)$ \\
\hline CYP3A5 6986GG & $6(85,7 \%)$ & $52(89,7 \%)$ \\
\hline
\end{tabular}

Примечание: * $\chi^{2}=0,101 ; p=1,0$

частот, позволяющее определить за счет чего образуется основное различие.

Распределение генотипов полиморфизма СУРЗА5 6986A>G (rs776746) между группами процентного изменения ПВ статистически значимо не различалось $\left(\chi^{2}=0,101 ; p=1,0\right)$ (табл. 5).

\section{ОБСУЖДЕНИЕ РЕЗУЛЬТАТОВ}

В связи с частым использованием в клинической практике лекарственных средств, служащих субстратами P-gp, изучение влияния полиморфизмов гена $A B C B 1$ на фармакодинамические и фармакокинетические особенности лекарственных средств представляет большой интерес.

На сегодняшний день влияние полиморфизмов гена ABCB1 на фармакодинамические особенности разных лекарственных средств изучается многими учеными. Так, была исследована связь между полиморфизмом АBCB1 3435С>T и ответом на антиретровирусную терапию у ВИЧ-1 инфицированных пациентов ( $n=123)$, получавших эфавиренз или нелфинавир [16]. Авторы обнаружили, что пациенты с аллелью 3435Т имеют лучший ответ на антиретровирусную терапию. В другой работе не удалось найти связь между полиморфизмом ABCB1 3435C>T (rs1045642) и вирусологическими, иммунологическими реакциями на антиретровирусную терапию [17].

P-gp принимает также участие в транспорте противоэпилептических лекарственных средств [18]. При генотипировании по полиморфизму $A B C B 1$ 3435C>T (rs1045642) пациентов, страдающих эпилепсией $(n=315)$, было обнаружено, что у больных с резистентностью $\mathrm{k}$ противоэпилептической фармакотерапии чаще наблюдается носительство генотипа ABCB1 3435CC, по сравнению с пациентами, показывающими положительный ответ на противоэпилептическую лекарственную терапию [19].

Полиморфизм гена СУРЗА5 может вносить вклад в вариабельность клиренса субстратов для СҮРЗА5. При изучении влияния экспрессии СҮРЗАБ на фармакологический ответ статинов показано, что ловастатин, симвастатин и аторвастатин были значимо менее эффективны у экспрессоров СҮРЗА5, чем у неэКспрессоров СҮРЗА5 [20].

В нашем исследовании, также посвященном изучению влияния носительства полиморфизмов генов ABCB1 и СУРЗА5 на фармакодинамику лекарственного средства, в частности ривароксабана, было показано наличие статистически достоверной разницы по распределению генотипов полиморфизма ABCB1 3435C>T (rs1045642) между группой с \% $\triangle П \mathrm{~B} \leq 0$ и группой с $\% \Delta П \mathrm{~B}>0$. Наиболее значимый вклад в эту разницу вносят пациенты (85,7\%) с генотипом $A B C B 13435$ CТ в группе с $\% \triangle \Pi \mathrm{B} \leq 0$, что может указывать на отсутствие у данных пациентов клинического эффекта ривароксабана в стандартной дозе.

Среди участников нашего исследования преимущественно были выявлены пациенты с генотипом CYP3А5 6986GG (89,2\%), у которых изофрермент СҮРЗА5 полностью не экспрессируется. Статистически значимой разницы по распределению генотипов полиморфизма СУРЗА5 6986A>G (rs776746) между группой с \% с \% $\triangle П \mathrm{~B}>0$ обнаружено не было, что предположительно может быть связано с меньшей степенью участия изофермента СҮРЗА5, по сравнению с мембранным транспортером Р-gр, в фармакокинетике ривароксабана.

Учитывая обнаруженное нами влияние полиморфизма ABCB1 3435C>T (rs1045642) на процентное изменение ПВ под влиянием ривароксабана, актуальным представляется 
изучение не только фармакодинамики, но и фармакокинетики ривароксабана у пациентов с разными генотипами.

\section{ВЫВОДЫ}

Выявлено высокодостоверное статистически значимое влияние полиморфизма АBCB1 3435C>T (rs1045642) на характер изменения ПВ у пациентов, получающих с целью тромбопрофилактики ривароксабан после эндопротезирования крупных суставов нижних конечностей. Между полиморфизмом СҮРЗА5 6986A>G (rs776746) и процентным изменением ПВ статистически значимой связи обнаружено не было. В перспективе разработки данной темы целесообразно изучение не только фармакодинамики, но и фармакокинетики ривароксабана у пациентов с разными генотипами.

Финансирующая организация не принимала участия в создании дизайна исследования, сборе, анализе, интерпретации данных, написании рукописи и решении о подаче рукописи для публикации.

\section{Литература}

1. Geerts WH, Heit JA, Clagett GP, Pineo GF, Colwell CW, Anderson FA Jr et al. Prevention of venous thromboembolism Chest. 2001; 119 (1): 132-75.

2. Agnelli G. Prevention of venous thromboembolism in surgical patients. Circulation. 2004; 110 (24 Suppl 1): 4-12.

3. Кавалерский Г. М., Середа А. П., Мурылев В. Ю., Рукин Я. А., Гаврилов А. В., Архипов И. В. и др. 2D-планирование эндопротезирования тазобедренного сустава. Травматология и ортопедия России. 2015; 4 (78): 95-102.

4. New Drug Application (NDA) of the Federal Food, Drug, and Cosmetic Act (FDCA) for Xarelto ${ }^{\circledR}$ (rivaroxaban) 10 mg immediate release Tablets, for the prophylaxis of deep vein thrombosis and pulmonary embolism in patients undergoing: hip replacement surgery or knee replacement surgery [Internet]. 2008 July [cited 2018 Aug 1]. Available from: https://www.accessdata.fda.gov/ drugsatfda_docs/appletter/2011/022406s000ltr.pdf.

5. European Medicines Agency. Doc.Ref.: EMEA/543519/2008. CHMP assessment report for Xarelto. [Internet]. 2008 [cited 2018 Aug 1]. Available from: http://www.ema.europa.eu/docs/ en_GB/document_library/EPAR_-_Public_assessment_report/ human/000944/WČ500057122.pdf.

6. Fromm MF. Importance of P-glycoprotein at blood-tissue barriers. Trends Pharmacol Sci. 2004; 25 (8): 423-9.

7. GeneCards: The Human Gene Database. ABCB1 Gene [Internet]. [cited 2018 Aug 1]. Available from: https://www.genecards.org/ cgi-bin/carddisp.pl?gene=ABCB1

8. Wang D, Johnson AD, Papp AC, Kroetz DL, Sadée W. Multidrug resistance polypeptide 1 (MDR1, ABCB1) variant 3435C>T affects mRNA stability. Pharmacogenet Genomics. 2005; 15 (10): 693-704

9. Lamba J, Hebert JM, Schuetz EG, Klein TE, Altman RB. PharmGKB summary: very important pharmacogene information for CYP3A5. Pharmacogenet Genomics. 2012; 22 (7): 555-8.

10. Eriksson BI, Borris LC, Friedman RJ, Haas S, Huisman MV, Kakkar AK et al. Rivaroxaban versus enoxaparin for thromboprophylaxis after hip arthroplasty. N Engl J Med. 2008; 358 (26): 2765-75.

\section{References}

1. Geerts WH, Heit JA, Clagett GP, Pineo GF, Colwell CW Anderson FA Jr et al. Prevention of venous thromboembolism. Chest. 2001; 119 (1): 132-75.

2. Agnelli G. Prevention of venous thromboembolism in surgical patients. Circulation. 2004; 110 (24 Suppl 1): 4-12.

3. Kavalerskij GM, Sereda AP, Murylev VJu, Rukin JaA, Gavrilov AV Arhipov IV, i dr. 2D-planirovanie jendoprotezirovanija tazobedrennogo sustava. Travmatologija i ortopedija Rossii. 2015; 4 (78): 95-102.

4. New Drug Application (NDA) of the Federal Food, Drug, and Cosmetic Act (FDCA) for Xarelto ${ }^{\circledR}$ (rivaroxaban) 10 mg immediate release Tablets, for the prophylaxis of deep vein thrombosis and pulmonary embolism in patients undergoing: hip replacement
11. Kakkar AK, Brenner B, Dahl OE Eriksson Bl, Mouret P, Muntz J et al. Extended duration rivaroxaban versus short-term enoxaparin for the prevention of venous thromboembolism after total hip arthroplasty: a double-blind, randomised controlled trial. Lancet. 2008; 372 (9632): 31-9.

12. Lassen MR, Ageno W, Borris LC, Lieberman JR, Rosencher N, Bandel TJ et al. Rivaroxaban versus enoxaparin for thromboprophylaxis after total knee arthroplasty. N Engl J Med. 2008; 358 (26): 2776-86.

13. Turpie AG, Lassen MR, Davidson BL, Bauer KA, Gent M, Kwong LM et al. Rivaroxaban versus enoxaparin for thromboprophylaxis after total knee arthroplasty (RECORD4): a randomised trial. Lancet. 2009; 373 (9676): 1673-80.

14. Инструкция по медицинскому применению лекарственного средства Ксарелто ${ }^{\circledR}$ В Российской Федерации. Регистрационный номер: ЛСР-009820/09.

15. Online Encyclopedia for Genetic Epidemiology studies. HardyWeinberg equilibrium calculator [Internet]. [cited 2018 Dec 12]. Available from: http://www.oege.org/software/hwe-mr-calc.shtml

16. Fellay J, Marzolini C, Meaden ER, Back DJ, Buclin T, Chave JP et al. Response to antiretroviral treatment in HIV-1-infected individuals with allelic variants of the multidrug resistance transporter 1: a pharmacogenetics study. Lancet. 2002; 359 (9300): 30-6.

17. Nasi M, Borghi V, Pinti M, Bellodi C, Lugli E, Maffei S. MDR1 C3435T genetic polymorphism does not influence the response to antiretroviral therapy in drug-naive HIV-positive patients. AIDS. 2003; 17 (11): 1696-8.

18. Löscher W., Potschka $H$. Role of multidrug transporters in pharmacoresistance to antiepileptic drugs. J Pharmacol Exp Ther. 2002; 301 (1): 7-14.

19. Siddiqui A, Kerb R, Weale ME, Brinkmann U, Smith A, Goldstein DB. Association of multidrug resistance in epilepsy with a polymorphism in the drug-transporter gene ABCB1. N Engl J Med. 2003; 348 (15): 1442-8.

20. Kivistö KT, Niemi M, Schaeffeler E, Pitkälä K, Tilvis R, Fromm MF. Lipid-lowering response to statins is affected by CYP3A5 polymorphism. Pharmacogenetics. 2004; 14 (8): 523-5.

surgery or knee replacement surgery [Internet]. 2008 July [cited 2018 Aug 1]. Available from: https://www.accessdata.fda.gov/ drugsatfda_docs/appletter/2011/022406s000ltr.pdf.

5. European Medicines Agency. Doc.Ref.: EMEA/543519/2008. CHMP assessment report for Xarelto. [Internet]. 2008 [cited 2018 Aug 1]. Available from: http://www.ema.europa.eu/docs/ en_GB/document_library/EPAR_-_Public_assessment_report/ human/000944/WC500057122.pdf.

6. Fromm MF. Importance of P-glycoprotein at blood-tissue barriers. Trends Pharmacol Sci. 2004; 25 (8): 423-9.

7. GeneCards: The Human Gene Database. ABCB1 Gene [Internet]. [cited 2018 Aug 1]. Available from: https://www.genecards.org/ cgi-bin/carddisp.pl?gene=ABCB1. 
8. Wang D, Johnson AD, Papp AC, Kroetz DL, Sadée W. Multidrug resistance polypeptide 1 (MDR1, ABCB1) variant 3435C>T affects mRNA stability. Pharmacogenet Genomics. 2005; 15 (10): 693-704.

9. Lamba J, Hebert JM, Schuetz EG, Klein TE, Altman RB. PharmGKB summary: very important pharmacogene information for CYP3A5. Pharmacogenet Genomics. 2012; 22 (7): 555-8.

10. Eriksson BI, Borris LC, Friedman RJ, Haas S, Huisman MV, Kakkar AK et al. Rivaroxaban versus enoxaparin for thromboprophylaxis after hip arthroplasty. N Engl J Med. 2008; 358 (26): 2765-75.

11. Kakkar AK, Brenner B, Dahl OE, Eriksson BI, Mouret P, Muntz J et al. Extended duration rivaroxaban versus short-term enoxaparin for the prevention of venous thromboembolism after total hip arthroplasty: a double-blind, randomised controlled trial. Lancet. 2008; 372 (9632): 31-9.

12. Lassen MR, Ageno W, Borris LC, Lieberman JR, Rosencher N, Bandel TJ et al. Rivaroxaban versus enoxaparin for thromboprophylaxis after total knee arthroplasty. N Engl J Med. 2008; 358 (26): 2776-86.

13. Turpie AG, Lassen MR, Davidson BL, Bauer KA, Gent M, Kwong LM et al. Rivaroxaban versus enoxaparin for thromboprophylaxis after total knee arthroplasty (RECORD4): a randomised trial. Lancet. 2009; 373 (9676): 1673-80.
14. Instrukcija po medicinskomu primeneniju lekarstvennogo sredstva Ksarelto $^{\circledast} \vee$ Rossijskoj Federacii. Registracionnyj nomer: LSR009820/09.

15. Online Encyclopedia for Genetic Epidemiology studies. HardyWeinberg equilibrium calculator [Internet]. [cited 2018 Dec 12]. Available from: http://www.oege.org/software/hwe-mr-calc.shtml

16. Fellay J, Marzolini C, Meaden ER, Back DJ, Buclin T, Chave JP et al. Response to antiretroviral treatment in HIV-1-infected individuals with allelic variants of the multidrug resistance transporter 1: a pharmacogenetics study. Lancet. 2002; 359 (9300): 30-6.

17. Nasi M, Borghi V, Pinti M, Bellodi C, Lugli E, Maffei S. MDR1 C3435T genetic polymorphism does not influence the response to antiretroviral therapy in drug-naive HIV-positive patients. AIDS. 2003; 17 (11): 1696-8.

18. Löscher W., Potschka $H$. Role of multidrug transporters in pharmacoresistance to antiepileptic drugs. J Pharmacol Exp Ther. 2002; 301 (1): 7-14.

19. Siddiqui A, Kerb R, Weale ME, Brinkmann U, Smith A, Goldstein DB. Association of multidrug resistance in epilepsy with a polymorphism in the drug-transporter gene ABCB1. N Engl $J$ Med. 2003; 348 (15): 1442-8.

20. Kivistö KT, Niemi M, Schaeffeler E, Pitkälä K, Tilvis R, Fromm MF. Lipid-lowering response to statins is affected by CYP3A5 polymorphism. Pharmacogenetics. 2004; 14 (8): 523-5. 